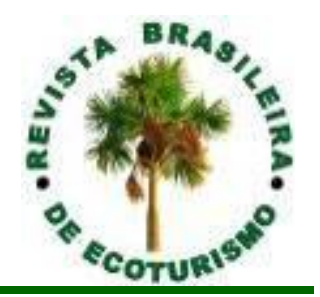

\title{
E o Turismo do Mandacaru com o farol (temporariamente) fechado?!? Percepções da comunidade - atores da atividade
}

\section{And the Mandacaru's Tourism with the lighthouse (temporarily) closed?!? Community`s perceptions - actors of the activity}

\author{
Marcelo Aragão Saldanha, Leonardo Augusto Lobato Bello, \\ Sílvia Helena Ribeiro Cruz, Monique Oliveira Serra
}

\begin{abstract}
RESUMO: O trabalho objetiva inicialmente, caracterizar o importante atrativo turístico/cultural farol das Preguiças, popularmente chamado de farol do Mandacaru, construído pela Marinha do Brasil em 1940, e estabelecido na cidade de Barreirinhas/MA, junto ao povoado ribeirinho de mesmo nome. Encontrando-se temporariamente fechado, visto o comprometido estado da sua construção, tem afetado diretamente os ganhos inerentes a atividade turística - sendo ele, já por muitos anos, uma habitual parada do circuito Pequenos Lençóis. No que tange a busca de respostas para a compreensão das percepções da comunidade, visto as dificuldades ora vividas, se aplica um questionário estruturado (de características mais qualitativas), provido de 10 (dez) indagações, entre abertas e fechada. Quanto aos resultados obtidos, estes apontam para as evidências de uma significativa interrupção na dinâmica da economia do lugarejo, que tem no Turismo, a sua oportunidade motriz.
\end{abstract}

PALAVRAS CHAVE: Farol; Mandacaru; Barreirinhas; Percepções da comunidade; Turismo.

ABSTRACT: This work has one bigger objective to characterize the important cultural tourist attraction, built by the Brazilian Navy in 1940 and established in the city of Barreirinhas/MA in the riverside village of the same name. Being temporarily closed, due to the compromised state of its construction, it has affected the gains of the tourist activity - being, for many years, a habitual stop of the circuit Pequenos Lençóis. Regarding the search for answers to the understanding of community perceptions, given the difficulties now experienced, a structured questionnaire (of more qualitative characteristics) with 10 (ten) open/closed questions apllied. As for the results obtained, they point to the evidences of an interruption of the local economy, which has in Tourism its greatest opportunity.

KEYWORDS: Lighthouse; Mandacaru; Barreirinhas; Community perceptions; Tourism. 


\section{Introdução}

Tal artigo, se vale do objetivo primeiro de caracterizar o importante atrativo turístico/cultural farol das Preguiças, popularmente chamado de farol do Mandacaru, construído pela Marinha do Brasil em 1940, e estabelecido na cidade de Barreirinhas/MA, junto ao povoado ribeirinho de mesmo nome, à margem esquerda do rio Preguiças, bem próximo a sua foz; ao instante, que se apropriando das percepções da comunidade, propõe, sobretudo, discutir as eventuais perdas contabilizadas, dado o fecho temporário das suas atividades, desde a Capitania dos Portos do estado do Maranhão, em Março de 2019 (portanto, a pouco mais de um ano), movido pelo comprometido estado da sua construção - o farol que é, já por muitos anos, uma habitual parada do circuito Pequenos Lençóis, uma composição irrestrita dos roteiros turísticos do destino.

O estudo proposto é didaticamente segmentado em três abordagens distintas e complementares. A primeira delas, se encarrega de situar o atrativo em questão (objeto do estudo), junto ao povoado do Mandacaru, dando a ambos, traços mais característicos. Na sequência, apresenta-se o problema ora vivido pela população local e pela própria atividade turística, ele que culminou com o fecho das suas operações, afetando diretamente os ganhos inerentes a dinâmica da economia criativa do lugar - sendo estes "prejuízos", por fim, elencados a partir das respostas construídas junto a pesquisa de campo realizada - percepções da comunidade, apontando os resultados obtidos, para as evidências de uma significativa interrupção, naquilo que se reconhece como oportunidade motriz do lugarejo - a força do Turismo.

\section{Fundamentação teórica}

\section{Caracterização da área de estudo}

\section{A cidade (sede) turística de Barreirinhas}

Segundo os dados do Instituto Brasileiro de Geografia e Estatística (2018), a cidade de Barreirinhas detém uma área territorial de aproximadamente 3048 quilômetros quadrados, abrigando neste espaçamento, quase a metade do Parque Nacional dos Lençóis Maranhenses, e se localiza no nordeste do estado do Maranhão, na mesorregião do Norte, na microrregião da Baixada Oriental ou dos Lençóis Maranhenses, distando cerca de 270 quilômetros à leste, da capital São Luís.

Sua população soma um pouco mais de 60 mil habitantes residentes e, apesar de possuir um núcleo urbano em vias de organização, a grande maioria dela, ainda vive em comunidades ribeirinhas e na zona rural, sendo notado também, um contingente populacional sazonal, que aumenta consideravelmente em tempos de feriados e férias.

Em observância ao Relatório de Zoneamento e Plano Estratégico de Desenvolvimento do Turismo do estado do Maranhão, "[...] a cidade é provida de um regime pluviométrico que define duas estações anuais, uma chuvosa (janeiro a junho) e outra seca (julho a dezembro)" (SECRETARIA DE TURISMO DO ESTADO DO MARANHÃO, 2010, p.89), possuindo uma temperatura média de 26 graus Celsius, com ventos provenientes do litoral. 
É uma região rica na produção do buriti, sendo o fruto produzido por uma palmeira regional, que se desenvolve em terrenos alagados mais baixos, normalmente às margens dos igarapés e rios, e a sua fibra, comumente utilizada desde a produção (na grande maioria das vezes, encaminhada por mulheres - que assim complementam as suas rendas domésticas) do criativo artesanato do lugar.

A pesca ainda responde por um papel importante junto a economia, especialmente no que tange a subsistência das comunidades mais pobres - famílias inteiras comercializam os seus excedentes, no cais da cidade, à beira do rio Preguiças, principal via fluvial da região, ele que nasce no povoado Barra da Campineira, em Anapurus, e deságua no Oceano Atlântico, em frente a comunidade litorânea de Atins.

Ao lado desta prática, os citadinos também sobrevivem do cultivo da castanha do caju, visto a exportação para o vizinho estado do Ceará, sendo ela, o mais importante produto agrícola do lugar, assim como da fabricação artesanal da farinha de mandioca.

O comércio local é cada vez mais multifacetado, ainda existindo as antigas mercearias que se utilizam da "caderneta" para a tomada dos pedidos a serem pagos no mês seguinte, como também (e cada vez mais) as lojas grifadas de cosméticos, eletrodomésticos, medicamentos, óculos esportes e as operadoras de telefonia móvel.

Com o povoamento do município datado de 1850 e tendo sido elevada a categoria de Paróquia em 1858, Barreirinhas, foi segundo Ramos (2008) emancipada como cidade, em 1938, fazendo parte da comarca de Araióses, experimentando um primeiro surto de crescimento econômico, e também, de grande impacto ambiental, quarenta anos depois, no início da década de 70 , quando a Petrobrás fincou ali a sua bandeira, ensaiando a prospecção de petróleo e gás natural. Desta forma, o lugar tomado de otimismo, vislumbrava o término de todo o seu isolamento histórico.

Quanto a sua inclinação para a atividade turística, esta se revelou no término da década de 90 , e início daquela seguinte, dado o interesse da então gestão pública estadual, materializado no (polêmico) Plano de Desenvolvimento Integral do Turismo - o Plano Maior, de revelar para o mundo, o que comercialmente se constituía de um dos "Segredos do Brasil", portanto, o Parque Nacional dos Lençóis Maranhenses.

Desde Silva (apud FIBRAS, 2012, p.11) "[...] entre os anos de 2000 a 2007, a oferta dos meios de hospedagem esteve aumentada em $330 \%$, sendo eles, na sua maioria, propriedade de migrantes atraídos pelo Turismo ali instalado".

Acerca deste cenário, Yázigi (2003, p.127) trata com bastante clareza:

A estradinha de terra ganha asfalto; surge uma pequena pousada, um posto de gasolina, os prestadores de serviços turísticos, um restaurante; os carros chegam e os loteamentos também. A pressa em ganhar dinheiro fácil, aliada à displicência administrativa, que interpreta todo início de empreendimento, como fator de progresso. 
No que tange aos deslocamentos para o destino, até o início do ano de 2002, que antecede a construção da MA-402 (a Translitorânea), estrada que interliga a cidade às rodovias BR 135 e 222, chegar à Barreirinhas por meio do acesso literal por estrada de terra, significava viajar desconfortavelmente, e de maneira muito perigosa, visto, sobretudo, as travessias rudimentares dos igarapés e riachos, por um tempo aproximado de nove horas, em meio ao calor e a poeira, inerentes características do caminho.

Repetindo RAMOS (2019, p.194) "[...] com a construção da Translitorânea, o trajeto foi encurtado em mais de 100 quilômetros e impulsionou, consideravelmente o Turismo na região".

Em Janeiro de 2014, investimentos da ordem de 4 milhões de Reais, aportados pelo governo federal, através do Ministério do Turismo, culminam com a homologação da parte da Agência Nacional de Aviação Civil (ANAC), do aeroporto da cidade, podendo a partir de então, ser ele operado por rotas áreas regulares e vôos "charters", fretados por grandes operadoras turísticas (o que até hoje, passados seis anos, nunca aconteceu), encurtando ainda mais, as distâncias todas e maximizando a diversidade da demanda.

\section{Em Barreirinhas, o pacato povoado do Mandacaru... e ali, o militar, histórico (e também turístico) farol das Preguiças}

O distrito do Mandacaru, que segundo os seus moradores mais antigos, detém este nome, visto a grande incidência da tal vegetação, existente ali, em tempos passados, distante cerca de 26 quilômetros da sede do município de Barreirinhas (sendo o percurso feito, sobretudo, em lanchas movidas a motor de popa - as "voadeiras", numa viagem que dura cerca de 45 minutos), e logo em frente a ilha do Farol, ainda figura-se como uma autêntica vila de pescadores, em meio aos buritizais - a "jóia" dos Lençóis (pois importante fonte de renda para os seus citadinos), aos juçarais e as áreas de mangue, situando-se à margem esquerda do rio Preguiças, próximo da sua foz, no vizinho povoado do Atins, tendo sido ela, segundo os estudos de FEITOSA (2015, p.62) "[...] a primeira povoação edificada naquele entorno, podendo-se estimar a sua fundação, ao final do século XVIII".

Desde LIMA (2006, p.44), "[...] o Mandacaru dispõe de pequena infraestrutura, provida de energia elétrica, escola de ensino fundamental, posto de saúde e telefonia. O comércio, ainda incipiente, localiza-se junto do farol - o centro do lugar."

Atualmente provida, de aproximadamente um mil e quinhentos habitantes, o que the caracteriza como um dos concentrados populacionais mais importantes da região, os nativos dali, se constituem de uma gente muito humilde, que sobrevive basicamente da pesca, e também da fabricação das embarcações/marcenaria naval (é possível lá encontrar, alguns estaleiros em funcionamento), sendo o povoado, o maior produtor de caranguejo da região, e mais recentemente (desde o fim da década de 90), da exploração do Turismo - entretanto, de uma gente muito animada, que celebra as já tradicionais festas do caranguejo e do pescador (no mês de Julho), que promove disputas de futebol nos campos de areia, desde os fins de semana, e que, assiduamente, renova a sua fé, participando das missas, quando o pároco da matriz de Barreirinhas, decide por aquelas bandas incursionar.

O artesanato produzido no Mandacaru tem características muito peculiares, o que o torna absolutamente demandado, visto a matéria prima utilizada pelas 
mulheres artesãs (que também se encarregam do ofício de "tirar o marisco") cascalhos e conchas das beiras das praias, e do próprio rio (que sofre muita influência das marés). Deles, são produzidos bijuterias, cortinas, luminárias, quadros, e tantos outros produtos, que encantam os visitantes.

Entretanto, o que mais "salta aos olhos" da atividade turística do lugar é mesmo o farol das Preguiças ou farol do Mandacaru (como, por todos é chamado) um monumento tipo torre troncônica de concreto armado, com 45 metros de altura e uma quase duas centenas de estreitos degraus (160, precisamente), dispostos em uma escadaria circular/íngreme, tendo sido construído pela Marinha do Brasil, em 1940, e inaugurado quatro anos após, pelo almirante Moraes Rego, com o intento, até então único, de orientar os navegantes, visto o potente facho de luz intermitente com alcance luminoso de 43 milhas, que dele emanava por todas as noites, assinalando desta feita, a barra e os baixos rochosos da foz do rio que the dera 0 nome.

Desde RAMOS (2019, p.445), "[...] antes daquela obra inaugurada, existia ali, um outro farol em ferro, todo gradeado e provido de seis colunas que o sustentavam, tendo ele, cerca de 30 metros de altura [...]".

O historiador ainda complementa afirmando que "[...] um empregado de nome Catarino, detinha a responsabilidade diária de abastecê-lo, com aproximadamente 10 litros de querosene, mantendo-o assim, devidamente aceso".

Lima (2006) explicita que por muito tempo, ouviu-se entre os mais idosos do lugarejo, que quando desta construção (a primeira delas), visto uma falha nos cálculos estruturais, a empreitada recém iniciada veio abaixo, e confuso, o engenheiro responsável encaminhou a planta ao Rio de Janeiro, para ser então reestruturada. Neste meio tempo, até que retornasse ao Mandacaru, o mestre de obras, semianalfabeto, mas muito experiente, seguiu com o término da torre, inaugurando-a um mês depois, junto das mais altas patentes da corporação, tendo o engenheiro, logrado todos os cumprimentos inerentes ao feito.

Tsuji (2004), afirma que até os anos 1970, do século passado, havia uma linha regular (muito rudimentar) de barcos, que saía diariamente de São José de Ribamar (cidade balneária, vizinha a capital São Luís) com destino a Barreirinhas, passando pelas ilhas do Carrapatal e do Mangue, pelo Atins e pelo Mandacaru. Depois de muitas horas, de uma viagem exaustiva e perigosa, debaixo de um sol tórrido ou de fortíssimas chuvas, avistar o cume do farol ao longe, era a certeza da chegada com segurança - isto também o envolve de um imensurado valor histórico, dadas as incontáveis memórias construídas de toda a sua gente.

Do pequeno terraço deste monumento militar/histórico, descortina-se uma espetacular vista panorâmica de 360 graus - segundo RAMOS (2019, p.445), "[...] uma visão exuberante do Caburé, do rio Preguiças e dos seus manguezais, do oceano Atlântico e do Canto do Atins, bem no início dos Lençóis Maranhenses [...]", sendo, exatamente, toda esta cenografia natural única, que visto a chegada dos turistas, altera de maneira muito significativa a própria dinâmica da economia daquele povo ribeirinho - figurando assim, uma nova força motriz de produção, toda dependente daquela construção, já inteiramente entendida como uma (cada vez mais) habitual parada do circuito Pequenos Lençóis, como uma composição irrestrita dos roteiros turísticos do destino (Figura 1). 


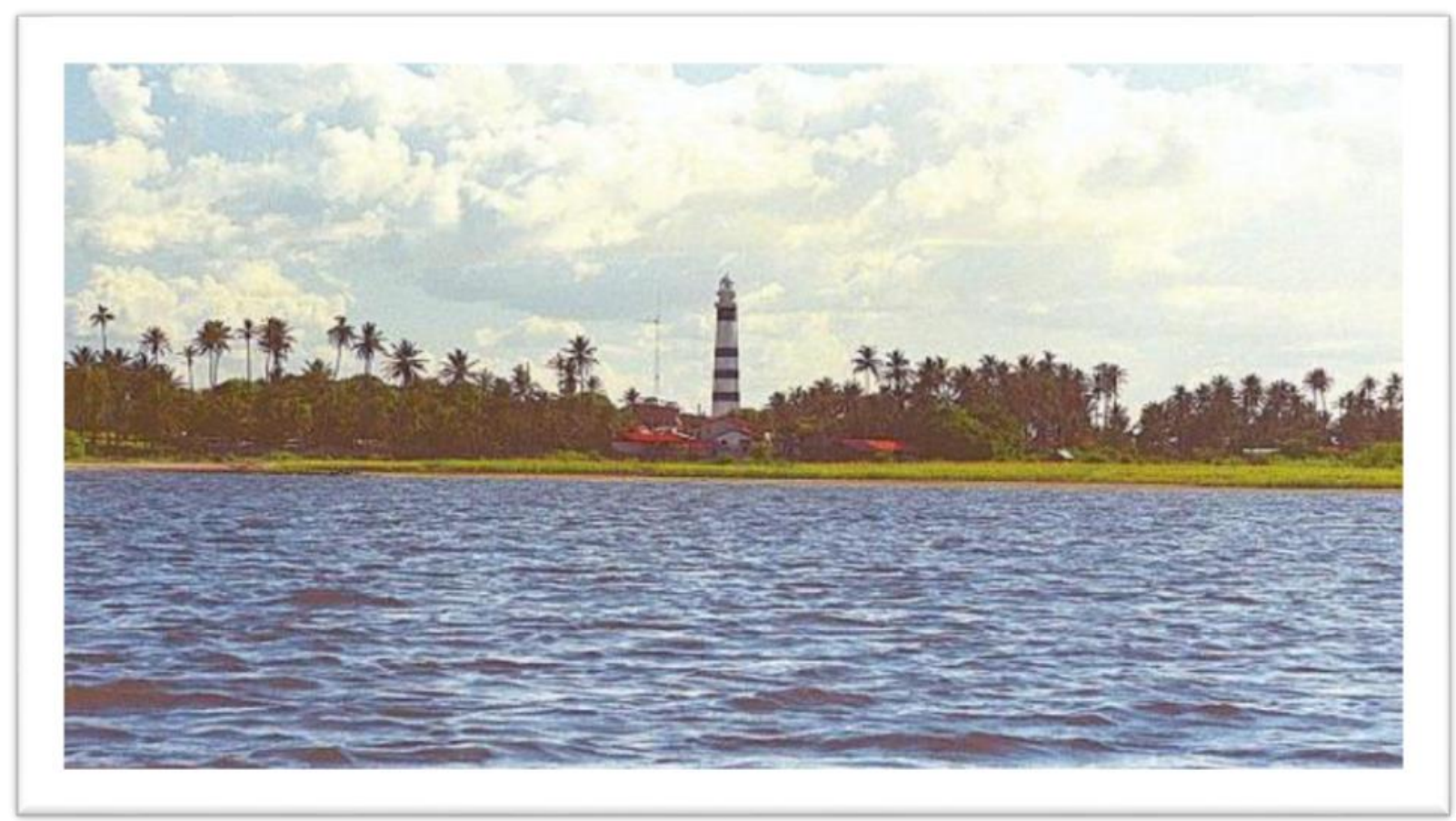

Figura 1: $O$ farol das Preguiças à beira do rio de mesmo nome

Figure 1: The Preguiças lighthouse near the river with the same name

Fonte: autores (2019)

Source: authors (2019)

\section{Em Março de 2019, o necessário fecho (temporário) do farol das Preguiças}

Em Março de 2019 (portanto, a pouco mais de um ano), a Marinha do Brasil, através da Capitania dos Portos do estado do Maranhão, responsável pelas operações do monumento, em todo o tempo da sua existência (salvo num instante histórico, que uma concessão para fins de administração particular fôra tratada uma taxa pré fixada era cobrada para o acesso, ficando o farol das Preguiças sob os cuidados de um empresário do segmento da restauração, e também membro da Sociedade dos Amigos da Marinha do estado do Maranhão/SOAMAR, ele que vivia com a sua família, no povoado vizinho do Caburé), sob a deliberação expressa do seu então capitão dos portos - o comandante Márcio Dutra (atualmente, já substituído), decide sobre o seu fecho total.

Quaisquer acessos a sua estrutura interna (exceto suas áreas de terreno externo), foram interrompidos, sem perspectivas de data para a sua reabertura, nem mesmo publicizando um eventual calendário (quadro de obras) necessário para o seu restauro, visto que o atrativo militar, histórico e turístico em questão, já por algum tempo, se mostrava em um comprometido estado da sua construção - pois repleto de consideráveis rachaduras em toda a extensão do seu edifício, justificando a imprecisão destas pontuações, na completa inexistência de um orçamento institucional para (Figura 2). 


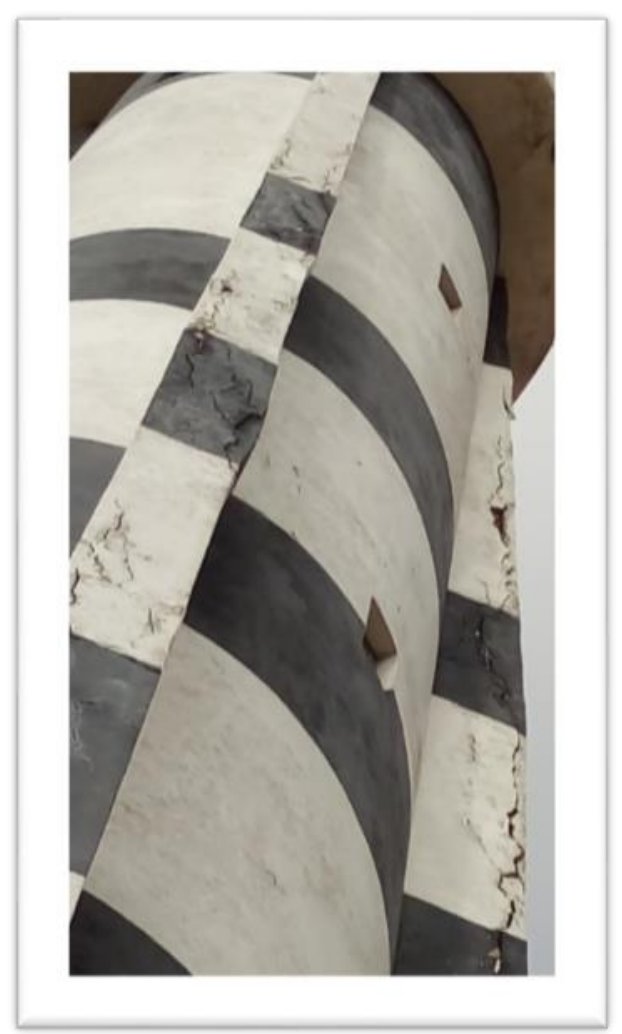

Fotografia 2: O farol das Preguiças com rachaduras em sua torre Photo 1: The Preguiças lighthouse with cracks in your tower

Fonte: autores (2019)

Source: authors (2019)

Dada uma relativa pressão popular - sobretudo, objeto das mídias sociais (logo após esta deliberação que culminou com o seu fecho), atendendo a uma determinação do governo do estado do Maranhão, em articulação com as suas pastas da Cultura e do Turismo, a Secretaria Adjunta de Projetos (SEAPROJ), vinculada aquela de Infraestrutura, em 04 de Abril de 2019, desde a Concremat Engenharia, encaminhou uma equipe multidisciplinar de técnicos para um criterioso procedimento de vistoria do monumento, certificando-se assim, da possível existência de problemas em sua construção - tudo na disposição de que um projeto de reforma seqüencial (inclusive, custeado pelo próprio estado) fosse à Marinha do Brasil, o quanto antes apresentado.

Findados os trabalhos, os engenheiros e arquitetos envoltos, chefiados pelo dro. Haroldo Francisco Pereira Braga, concluem neste relatório detalhado, que não tendo sido observadas as devidas manutenções preventivas, e de todo, necessárias para aumento do seu tempo de vida útil, a edificação manifesta-se com inúmeras e sérias patologias, a saber: carbonatação (fissuras) do concreto; infiltração; eflorescência (manchas) nos revestimentos, bem como na alvenaria e no concreto e corrosão da armadura, ainda que apresentando-se em estado estável, sem sinais iminentes de colapso da estrutura, fazendo-se necessária, uma imediata intervenção (inclusive interna, desde a escada, esquadrias e forro/laje), com obras de recuperação, eliminando-se assim, agravamentos das condições já apresentadas, visto estarem elas, expostas às intempéries ambientais, com alto teor de cloretos - o que só agrava a consequente oxidação. 


\section{Material e Métodos}

\section{Caracterização da área de estudo}

O povoado do Mandacaru é o local destinado ao encaminhamento do estudo, especificamente desde a sua via principal, que segue o desembarque do porto acesso ao farol das Preguiças, onde estão localizadas as lojinhas de artesanato e doces regionais, mercearias (pequenos comércios interioranos), sorveterias, além de pequenos bares, sendo esta, atualmente, a área que se constitui do maior adensamento dos rústicos equipamentos turísticos dali. É válido também pontuar, que tal espaçamento é de todo múltiplo - em públicos frequentadores, uma vez que os nativos, ao lado dos turistas, também fazem uso dele.

\section{O procedimento da coleta dos dados}

Este se materializou com o uso do instrumental investigativo - aplicação de um questionário estruturado, disposto a partir de 10 (dez) perguntas, sendo uma delas, fechada (provida de desdobramentos) e as 09 (nove) seguintes, todas abertas.

É importante grifar, que as abordagens qualitativas se fazem evidência neste estudo, sempre presentes nas falas mais espontâneas dos próprios entrevistados, constantemente provocadas pelo pesquisador.

Todo este trabalho exploratório/descritivo ocorreu entre os meses de Outubro Novembro e Dezembro de 2019, em um tempo cronológico que sucede a alta estação turística última, uma das mais expressivas dos derradeiros anos, acontecida nos meses de Junho, Julho e Agosto de 2019, tendo se constituído a coleta amostral em um total de 10 (dez) entrevistas, sendo que cada uma delas, durava em média 60 (sessenta) minutos para a sua realização, com atores os mais diversos, mais didaticamente apresentados, no quadro sequencial:

Quadro 1: Atores da pesquisa (detalhamento da comunidade estudada)

Frame 1: Research actors (details of the studied community)

\begin{tabular}{|c|c|}
\hline ATORES da PESQUISA. & QUANTITATIVO \\
\hline (DETALHAMENTO da COMUNIDADE ESTUDADA) & 04 \\
\hline a) Artesãs. & 01 \\
\hline b) Pequeno comerciante - vendedor de bebidas, doces e sorvetes. & 01 \\
\hline c) Agente de viagens e Turismo Receptivo. & 01 \\
\hline d) Condutor turístico. & 01 \\
\hline e) Piloto de lancha. & 01 \\
\hline f) Superintendente estadual de Turismo para os pólos Lençóis e \\
Delta.
\end{tabular}

Fonte: autores (2020)

Source: authors (2020)

Acrescenta-se às informações enquadradas acima, que os atores entendidos como $a$ e $b$, habitam o povoado do Mandacaru; ao passo que aqueles nominados como $c, d, e, f$ e $g$, caracterizam-se pela direta relação com as operações da atividade em questão, sem habitar o núcleo estudado. 


\section{Resultados e Discussão}

\section{Questão fechada 1 (e seus desmembramentos)}

Por início, são caracterizados os 10 (dez) atores da pesquisa, visto alguns substratos - sendo a idade, o primeiro deles. A faixa etária média dos pesquisados, incluindo aí, as próprias artesãs, é de 40 (quarenta) anos, tempo muito associado ao próprio desenvolvimento do Turismo na região, que se dá, desde os fins dos anos 90.

Quanto a escolaridade, 30\% dos entrevistados têm curso superior, outros 30\% têm curso médio completo, ao passo que os $40 \%$ restantes (algumas artesãs e piloto de lancha), se dividem entre os ensinos fundamental e médio incompleto.

Tendo sido indagados se mora e trabalha (com Turismo) no Mandacaru, $50 \%$ do universo da pesquisa, afirma que SIM (sendo eles, as artesãs e o vendedor de bebidas, doces e sorvetes), ao passo que os demais - agente de viagens, condutor turístico, coordenadora do Núcleo de Apoio Empresarial e gestora do Projeto Investe Turismo do SEBRAE, piloto de lancha e superintendente de Turismo do estado do Maranhão- pólos Lençóis e Delta, se utilizam da negativa, visto estarem domiciliados na sede do município, portanto em Barreirinhas.

No que diz respeito a figuração do trabalho, $10 \%$ enquadra-se como agente de viagens, $40 \%$ como artesã, $10 \%$ como condutor turístico, 10\% como piloto de lancha, $10 \%$ como vendedor de bebidas, doces e sorvetes e os últimos $20 \%$, constituem de outros.

Já no que concerne a renda (estimada) gerada (por mês) com o farol das Preguiças devidamente aberto, esta com foco nas artesãs (tão somente) oscila entre $R \$ 2.800,00$ (dois mil e oitocentos reais) médios na alta estação e $R \$ 800,00$ (oitocentos reais) médios na baixa estação, isto muito relativizado, segundo elas próprias, desde o estoque dos seus produtos.

Ainda limitando-se a derradeira indagação fechada às artesãs - detém outra renda, além da gerada desde o trabalho turístico?, 100\% delas afirmam que SIM, contribuindo (e até mesmo respondendo) no sustento das suas famílias, também nas condições de professora municipal, marisqueiras e vendedora de perfumes (de porta em porta) e roupas.

\section{Questões abertas 2/10}

Sequenciando a aplicação do questionário, seguem as indagações providas de características abertas, onde o pesquisador deixa os entrevistados (atores da pesquisa), mais libertos para construir os seus pensamentos, cumprindo-se, para tanto, um roteiro primeiramente estruturado.

A pergunta de número 2, enfatiza as tais memórias afetivas, aquelas do tempo de criança, possivelmente vividas neste espaçamento - entorno do farol das Preguiças, à beira do rio. Dos que ali habitam, alguns se criaram nestas redondezas, e para estes, as respostas foram mais envoltas em detalhamento, até mesmo em saudades de um tempo muito mais tranquilo (sem Turismo - ou com ele, ainda muito incipiente), logo diferente.

Uma das artesãs (na época, menina), disse observar o seu "pretendente" jogando bola, num campinho improvisado de areia ao pé do farol, o reconhecendo, 
portanto, como o "parque de diversões" do lugar, e que quando já cansados, buscavam a sombra de um cajueiro próximo para conversar. "[...] a área não era tão vigiada, como agora. Tínhamos a impressão de que tudo era como o nosso quintal." Em outros instantes, completava ela, "[...] os campeonatos de futebol atravessavam o rio, e aconteciam na ilha, em frente ao povoado."

Já uma outra entrevistada, afirma não ter tido tempo para nada disto "[...] cuidava dos filhos da professora primária, enquanto ela saía para o trabalho. Tinha afazeres domésticos, mesmo assim, adorava lavar as louças no girau da casa, junto daquele prédio tão alto."

Um agente de viagens, que sempre morou em Barreirinhas, remonta as suas férias escolares, quando por alguns dias instalados na praia do Caburé, tomava uma pequena lancha, rapidamente deslocando-se em família ao Mandacaru, com o intento de comprar, os já encomendados peixes bem frescos do seu Domingos e do seu Lauro, pescadores do vilarejo; bem como os caranguejos do seu Catarino, também marisqueiro dali, tudo isto acontecendo, sob a "observação do monumento", acrescentava ele.

O atual superintendente de Turismo do estado do Maranhão - pólos Lençóis e Delta, que também costumava veranear ali próximo (no povoado Moitas), levado por seus pais, ao Mandacaru, reaviva a figura do simpático José Lico, "[...] um administrador do farol - um oficial designado, que nos levava ao seu topo, para tirarmos fotos, e depois, mostrarmos entusiasmados aos colegas da capital."

E visto todas estas pontuações é apropriado ratificar que o farol das Preguiças, antes mesmo de ser (intencionalmente) um monumento militar e (fortuitamente) um atrativo turístico é, sobretudo, uma edificação de imensurado valor histórico, dadas as incontáveis lembranças construídas de toda a sua gente, tanto que no Junho de 2016, às vésperas das Olimpíadas, acontecidas do Rio de Janeiro, o monumento recebeu o fogo olímpico, que subiu até o seu terraço, desde as mãos de alguns dos filhos do Mandacaru - feito amplamente veiculado pelas mídias de todo o mundo.

Já o questionamento de número 3, elenca as possíveis impressões que os turistas levam para as suas casas, depois de subirem as escadarias do farol das Preguiças, avistando todo o rio do seu terraço, sendo estas, naturalmente verbalizadas para os atores pesquisados.

As respostas para tal indagação vão ao encontro de adjetivos os mais diversos, culminando todos para a valorada panorâmica, que se descortina então. "[...] mesmo sendo cansativo subir os quase duzentos degraus da escada circular, vale a pena parar aqui, e ver o visual lá de cima - é tudo lindo!!! A natureza foi espetacular!!! Tirei muitas fotos para postar nas mídias sociais.", sendo, em geral, o que ouvem, as artesãs, entre uma compra e outra dos visitantes.

Ainda assim, um condutor turístico escutado, refuta que muitos preferem não subir, alegando ter "medo de altura, e ainda pouco preparo físico", estes últimos, ressentindo-se, inclusive, da inexistência dos elevadores, restando para ambos os tipos, o aguardo do retorno do grupo, assim refrescando-se com os sorvetes caseiros de frutas regionais, comercializados logo em frente ao acesso da propriedade militar.

A pergunta de número 4, fôra feita exatamente assim: Você acredita que uma visita a vila, desprovida desta subida ao farol das Preguiças se faz completa? - 
sendo que $80 \%$ dos entrevistados (08 questionários) respondem que NÃO, alegando em sua totalidade, ser a vista proporcionada, o maior dos atrativos postos. Já os outros 20\% (02 questionários - estes, dos atores condutor turístico e piloto de lancha) alegam ser tudo muito relativo, dada a própria diversidade dos interesses das demandas, sendo útil ratificar que este último (e menos expressivo) percentual, não responde SIM, mas se utiliza da terminologia DEPENDE para compor as suas respostas.

Analisando a questão de número 5 - Em seu entendimento, o que aconteceu para que o farol das Preguiças, tivesse as suas portas fechadas à visitação pública, desde a determinação recente da Marinha do Brasil?, a totalidade dos entrevistados (todos os 10 questionários), alega o pouco cuidado do monumento, dispensado pela corporação militar que o responde de pronto (ainda que este, por muitos anos, seja utilizado para outros fins), sendo inclusive, mais enfáticos em suas respostas "[...] foi má gestão da Marinha do Brasil."

As artesãs e os comerciantes do lugar acrescentam, "[...] há anos atrás, era comum vermos uma grande embarcação deles, que parava no rio, e sobre ela, um helicóptero pousava, retirando pesadas estruturas de ferro para as reposições [...]" e sublinham, "[...] o trabalho de manutenção parou de acontecer aqui. Então, com os rebocos caindo, restou à eles, tomar esta medida de segurança."

De fato, em observância ao Relatório Técnico de Vistoria do Farol das Preguiças (2019), conclusivamente, a equipe de engenheiros e arquitetos, mobilizados por determinação do governo do estado do Maranhão, e de forma muito detalhada, laudou que "[...] não tendo sido observadas as devidas manutenções preventivas, e de todo, necessárias para aumento do seu tempo de vida útil, a edificação manifesta-se agora, com inúmeras e sérias patologias."

A pergunta de número 6 , deste modo se desenha: $E$ o que mudou por aqui, desde que isto aconteceu? Descreva o movimento recente da alta estação (Junho, Julho e Agosto de 2019) - aí, mais uma vez, a totalidade dos entrevistados (todos os 10 questionários), especialmente aqueles territorialmente estabelecidos na vila do Mandacaru, se ressentem de uma demanda decrescente, logo, de uma queda considerável no volume das suas vendas (artesanato, bebidas em geral, doces e sorvetes). "[...] os turistas já nem mais param conosco, eles seguem das Vassouras direto para o Caburé, e muitos (não todos) dos condutores e pilotos, dizem não ter mais o que fazer aqui.", relata as artesãs, sequenciando o desabafo "[...] e os poucos que ainda param, tem de quinze a vinte minutos destinados ao lugar [...] e indagando, "[...] quem é que vai comprar o nosso artesanato com toda esta correria? É má vontade deles (dos condutores e pilotos). Dizem, que nem cartões de crédito/débito temos, para facilitar as compras!!!" Já, segundo os pequenos comerciantes locais, "[...] muitos visitantes lamentam o farol está fechado, e não poderem usufruir do que compraram em seus pacotes turísticos."

Todas estas falam dos atores pesquisados, também já respondem (de modo afirmativo, e quase unânime) a indagação seqüencial de número 7: As agências de turismo receptivo deixaram de operar paradas neste lugar? Se SIM, o que elas alegam para? - sendo que, o que se conclui claramente é o pouco interesse dos condutores turísticos e pilotos de lancha (ainda que eles discordem disto), junto a efetivação da parada, muito mais do que a própria comercialização dos agentes de viagens (estes terceirizam aqueles, normalmente), que seguem fazendo-a, munidas dos cuidados de informar aos seus clientes, da impossibilidade de subida ao farol 
das Preguiças, sendo que o cenário momentaneamente estabelecido, acaba por gerar um "velado" conflito entre estas partes - portanto, artesãs e pequenos comerciantes versus condutores turísticos e pilotos de lanchas.

Logo, é apropriado pontuar que tudo o que ora se observa, diretamente afeta os ganhos inerentes à dinâmica da economia criativa do lugar - sendo estes "prejuízos" contabilizados, evidências de uma significativa interrupção, naquilo que, por muitos anos, se reconhece como oportunidade motriz do lugarejo - a força do Turismo.

E três, são os micro questionamentos que compõem a questão de número 8: Quem (qual empresa/entidade/órgão) você entende ser o responsável pela reforma/restauro do farol das Preguiças agora? Na sua cabeça, existe um desenho de reforma/restauro para ele? - o que você percebe ser necessário para agregar valor às visitas? Em todo o tempo que você vive/trabalha aqui, já viu alguma reforma/restauro serem feitos no farol das Preguiças?

Logo, $100 \%$ dos questionados acreditam ser a Marinha do Brasil, a responsável primeira pela reforma/restauro do monumento, ainda que alguns deles, tenham enfatizado uma possível parceria com governos estadual e municipal, sob o substrato valores aportados, justificando assim a obra.

Quanto a existência de um eventual desenho de reforma/restauro para o farol das Preguiças, são unânimes junto as tratativas de inclusão de certos equipamentos, a exemplo dos banheiros, do corredor de acesso à escadaria (formação de filas) com marquise abrigo/proteção para chuva e sol e dos recipientes apropriados para o armazenamento do lixo produzido.

Todos os entrevistados, também reconhecem a necessária urbanização da área compreendida entre o cais do porto e a entrada da zona militar (espaçamento que está localizado o farol), passando pela artéria comercial da vila - onde estão concentradas as artesãs, não desprovendo esta infraestrutura da acessibilidade para pessoas incapacitadas ou providas de mobilidades reduzidas.

O atual superintendente de Turismo do estado do Maranhão - pólos Lençóis e Delta, também ouvido nesta pesquisa, entende que um espaço/resgate da história do monumento, e da própria corporação que o responde, a exemplo de um museu interativo, também poderia agregar valor às visitas, aumentando assim, o tempo de permanência dos turistas no local.

Por fim, quanto a já terem visto alguma reforma/restauro serem feitos antes no farol das Preguiças, alguns dos indagados, sobretudo, os mais velhos, falam que estas já aconteceram em outros instantes (sem precisar quais), inclusive em consonância com os governos estaduais da época. Um agente de viagens, também ator deste estudo, relembra "pequenos reparos", a exemplo daqueles de 2016 (pelo próprio governo municipal), quando da passagem da tocha olímpica por ali..

Figurada desta maneira, a pergunta de número 9 - Você acredita que a população daqui, tem zelo (logo, se apropria) deste importante atrativo cultural/histórico/militar?, todos os escutados associam o farol das Preguiças à propriedade da Marinha do Brasil, se eximindo inclusive, de quaisquer cuidados. Alegam, especialmente aqueles, territorialmente estabelecidos na vila do Mandacaru, que os oficiais residentes, bem como a própria corporação militar, não conversam com eles, no sentido de provocar uma maior sensibilização. 
"[...] Os moradores, tanto não cuidam, que também estão sofrendo com o problema - falta mais engajamento da comunidade", fala o atual superintendente de Turismo do estado do Maranhão - pólos Lençóis e Delta, no que é de todo ratificado por uma das artesãs, "[...] cuidamos das nossas lojas, nos envolvemos com a produção do nosso artesanato, e acabamos por nos esquecer do que é comum a nós todas [...]" Não satisfeita, ainda acrescenta "[...] ficamos sempre à espera dos governos para resolver os nossos problemas."

:Terminando as perguntas do questionário aplicado, aquela de número 10 , evoca difusas possibilidades, quando da sua formulação: Na sua percepção, existem outros atrativos aqui, que podem ser mostrados ao visitante, além do farol das Preguiças? - compondo assim, um roteiro turístico mais completo? Se SIM, quais? Enumere.

Como respostas construídas, falam de belezas locais esquecidas (de certo, ofuscadas pela singularidade da vista proporcionada pelo farol), sobretudo no tempo que imediatamente sucede as chuvas, a exemplo da lagoa Morro dos Cajueiros; e daquela outra, provida de corredeiras, a Passagem dos Cavalos; além do estaleiro, já existente ali (produção de canoas) e da singela igreja de São Sebastião, o padroeiro do povoado.

$O$ agente de viagens pesquisado, fala que os turistas sentem faltam das experiências de base comunitária em toda a sua estada nos Lençóis Maranhenses, e também aqui "[...] eles querem participar das rotinas do homem nativo.", afirmando que isto poderia ser "posto nas prateleiras da atividade", também pelas marisqueiras do Mandacaru, que frequentemente saem "em bandos" coletando as conchas (os cascalhos) à beira do rio/mar, para depois materializarem criativamente as suas artesanias, de características inerentes ao lugar, a exemplo das bijuterias, cortinas, luminárias, quadros e tantos outros produtos. "[...] o visitante, antes mesmo da compra, se envolveria com parte da confecção - entendida como um tour, provido de características amplamente vendáveis.", trata ele.

Pensando nestas outras viabilidades de negócios, atreladas a necessária descoberta pelos próprios ativos da atividade turística da localidade, foi que ao longo de todo o dia 19 de Novembro de 2019, o SEBRAE Maranhão, articulado com outras instituições locais, a exemplo do IFMA Campus Barreirinhas, iniciou o projeto "Semear Mandacaru". A sua coordenadora do Núcleo de Apoio Empresarial e gestora do Projeto Investe Turismo, também partícipe desta pesquisa, reitera que este é o papel do órgão "[...] fomentar outros ganhos, empreender com mais criatividade e senso coletivo."

\section{Considerações Finais}

Acerca das percepções da comunidade do Mandacaru - atores da atividade turística, visto o farol (temporariamente) fechado (problema deste estudo), desde a Capitania dos Portos do estado do Maranhão, no último Março de 2019, movido pelo comprometido estado da sua construção, foram abordadas inúmeras evidências de um produto altamente impactado, dadas as perdas reais, daquela que já se constituía de uma habitual parada do circuito Pequenos Lençóis, uma composição irrestrita dos roteiros turísticos do destino, visto que dali se descortina uma espetacular vista panorâmica, uma visão exuberante do Caburé, do rio Preguiças e 
dos seus manguezais, do oceano Atlântico e do Canto do Atins - uma cenografia natural única.

Observando com critério, as diversas falas dos entrevistados, é notório concluir que o entrave, ora vivido pela população local e pela própria atividade turística, vem afetando diretamente os ganhos inerentes à dinâmica da economia criativa do lugar - sendo estes "prejuízos" por fim, elencados a partir das respostas construídas junto a pesquisa de campo realizada, ratificando os resultados conceituais obtidos, para as evidências de uma significativa interrupção, naquilo que se reconhece como oportunidade motriz do povoado - a força do Turismo.

É válido aqui, sublinhar que o que já fôra tratado; o farol das Preguiças, antes mesmo de ser (intencionalmente) um monumento militar e uma edificação de imensurado valor histórico, é (consequentemente, e por muito mérito) um atrativo turístico demandado, cabendo, portanto, as providências (discuti-las e responsabilizá-las, não é o intento do trabalho), de quem diz respeito - elas que devem culminar com a mais imediata retomada das suas atividades públicas vocacionadas.

\section{Referências}

FEITOSA, A.C. Lençóis Maranhenses, relação homem-ambiente na comunidade Ponta do Mangue, Barreirinhas - Maranhão: evolução geomorfológica da paisagem costeira leste do Maranhão, papel dos agentes naturais na modelagem do ambiente na foz do rio Preguiças. São Luís: Edufma, 2015.

FIBRAS e tramas de Barreirinhas. Rio de Janeiro: IPHAN, CNFCP, 2012. (sala do artista popular, n. 178)

INSTITUTO BRASILEIRO DE GEOGRAFIA E ESTATÍSTICA. Brasília, 2018. Disponível em: <www.cidades.ibge.gov.br>. Acesso em: 14 set. 2019.

LIMA, J.M.B. As belezas e os mistérios do rio Preguiças: Lençóis Maranhenses, explosão de vida. Barreirinhas: 2006. Segunda edição.

RAMOS, B. História de Barreirinhas: portal dos Lençóis Maranhenses. São Luís, 2008.

RAMOS, B. História de Barreirinhas: portal dos Lençóis Maranhenses. São Luís, 2019. Segunda edição.

SECRETARIA DE INFRAESTRUTURA DO ESTADO DO MARANHÃO. Relatório Técnico de Vistoria do Farol das Preguiças. Maranhão: Governo do Maranhão/SINFRA/SEAPROJ, 2019.

SECRETARIA DE TURISMO DO ESTADO DO MARANHÃO. Relatório de Zoneamento e Plano Estratégico de Desenvolvimento do Turismo do estado do Maranhão. São Luís: Governo do estado do Maranhão, 2010.

SILVA, D.L.B. Turismo em unidades de conservação: Contribuições para a prática de uma atividade turística sustentável no parque nacional dos Lençóis Maranhenses. Brasília: Universidade de Brasília, 2008.

TSUJI, T. Região dos Lençóis Maranhenses: Cenários futuros de ecoturismo e desenvolvimento sustentável. Curitiba: Juruá, 2004. 
YÁZIGI, E. A alma do lugar: turismo, planejamento e cotidiano em litorais e montanhas. São Paulo: Contexto, 2003.

Marcelo Aragão Saldanha: Instituto Federal do Maranhão, Barreirinhas, MA, Brasil.

E-mail: marceloaragaosaldanha@hotmail.com

Link para o currículo Lattes: http://lattes.cnpq.br/7157840590052692

Leonardo Augusto Lobato Bello: Universidade da Amazônia, Belém, PA, Brasil.

E-mail: leonardo.bello@unama.br

Link para o currículo Lattes: http://lattes.cnpq.br/5449459117793556

Sílvia Helena Ribeiro Cruz: Universidade Federal do Pará, Belém, PA, Brasil.

E-mail: silhcruz@gmail.com

Link para o currículo Lattes: http://lattes.cnpq.br/8432421463410679

Monique Oliveira Serra: Instituto Federal do Maranhão, Barreirinhas, MA, Brasil.

E-mail: monique.serra@ifma.edu.br

Link para o currículo Lattes: http://lattes.cnpq.br/3978370593618696

Data de submissão: 20 de dezembro de 2020

Data de recebimento de correções: 29 de fevereiro de 2020

Data do aceite: 29 de fevereiro de 2020

Avaliado anonimamente 